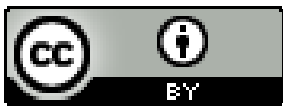

\title{
RACISMO E REGULARIZAÇÃO FUNDIÁRIA DOS TERRITÓRIOS DAS COMUNIDADES QUILOMBOLAS DA BAHIA
}

\author{
Paula Regina de Oliveira Cordeiro ${ }^{1}$
}

Resumo: A situação fundiária dos territórios quilombolas é dramática no Brasil. Esse estudo pretende, através do levantamento e síntese de dados e de reflexões teóricas argumentar que a não-regularização, a não-proteção e os conflitos nos territórios quilombolas estão inseridos na relação de poder estabelecida a partir da constituição do capitalismo contemporâneo. Para isso são trazidos alguns casos no Estado da Bahia, como os dos quilombos pesqueiros de Rio dos Macacos, de Dom João, de Graciosa e de São Franscisco do Paraguaçu. O racismo estrutural é, sem dúvida, o elemento explicativo de maior relevo para a não-proteção dos territórios quilombolas.

Palavras-chave: Racismo estrutural; Regularização fundiária; Territórios quilombolas.

\section{RACISM AND LAND REGULARIZATION OF THE TERRITORIES OF THE QUILOMBOLAS COMMUNITIES OF BAHIA}

\begin{abstract}
The land ownership situation in the quilombola territories is dramatic in Brazil. This study intends, through the survey and synthesis of data and theoretical reflections, to argue that non-regularization, non-protection and conflicts in quilombola territories are inserted in the power relationship established from the constitution of contemporary capitalism. For that, some cases are brought to the State of Bahia, such as the fishing quilombos of Rio dos Macacos, Dom João, Graciosa and São Franscisco do Paraguaçu. Structural racism is undoubtedly the most important explanatory element for the nonprotection of quilombola territories.
\end{abstract}

Keywords: Structural racism; Land regularization; Quilombola territories.

\footnotetext{
${ }^{1}$ Doutoranda no Programa de Pós-Graduação em Geografia da Universidade Federal da Bahia. Membro do Grupo Costeiros - Estudos Socioespaciais da Universidade Federal da Bahia e da Nova Cartografia Social - Núcleo de Estudos em Agroecologia da Universidade Federal do Recôncavo da Bahia. Atualmente é professora substituta da Universidade do Estado da Bahia. E-mail: paulareginacordeiro@gmail.com
}

Revista da ABPN • v. 12, n. Ed. Especial - Caderno Temático: "Geografias Negras"• abril de 2020, p. 32-53 
Resumen: La situación de la tierra de los territorios quilombolas es dramática en Brasil. Este estudio pretende, a través de la encuesta y síntesis de datos y reflexiones teóricas, argumentar que la no regularización, la no protección y los conflictos en los territorios quilombolas se insertan en la relación de poder establecida a partir de la constitución del capitalismo contemporáneo. Para ello, se traen algunos casos al Estado de Bahía, como los quilombos de pesca de Rio dos Macacos, Dom João, Graciosa y São Franscisco do Paraguaçu. El racismo estructural es sin duda el elemento explicativo más importante para la no protección de los territorios quilombolas.

Palabras clave: Racismo estructural; regularización de la tierra; territorios quilombolas.

\section{RACISME ET RÉGULARISATION DES TERRES DES TERRITOIRES DES COMMUNAUTÉS DE QUILOMBOLAS DE BAHIA}

Résumé: La situation foncière dans les territoires de quilombola est dramatique au Brésil. Cette étude entend, à travers l'étude et la synthèse des données et des réflexions théoriques, faire valoir que la non-régularisation, la non-protection et les conflits dans les territoires de quilombola sont insérés dans la relation de pouvoir établie à partir de la constitution du capitalisme contemporain. Pour cela, certains cas sont portés à l'État de Bahia, comme les quilombos de pêche de Rio dos Macacos, Dom João, Graciosa et São Franscisco do Paraguaçu. Le racisme structurel est sans aucun doute l'élément explicatif le plus important de la non-protection des territoires de quilombola.

Mots-clés: racisme structurel; Régularisation foncière; Territoires de Quilombola.

\section{INTRODUÇÃO}

Desde pelo menos a década de 1970, os povos e as comunidades tradicionais se colocam no cenário nacional afirmando suas identidades e seus territórios. Entre os povos e comunidades tradicionais do Brasil estão quilombolas, pescadores artesanais, marisqueiras e ribeirinhos. Segundo dados do Programa das Nações Unidas para o Desenvolvimento (PNUD), as Comunidades Tradicionais constituem aproximadamente cinco milhões de Brasileiros e ocupam um quarto do território nacional (SEPPIR, 2013), constituindo-se em significativa população no Brasil.

Revista da ABPN • v. 12, n. Ed. Especial - Caderno Temático: "Geografias Negras"• abril de 2020, p. 32-53 

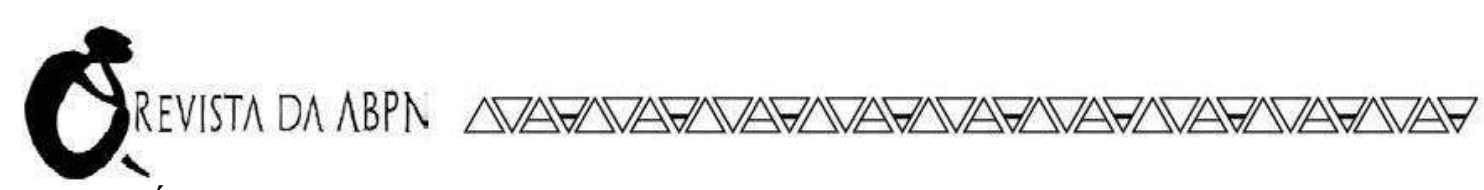

É fundamental apreender que o aparecimento dos povos e das comunidades tradicionais é político (MARTINS, 1993). Como afirma Alex Ratts (2004): "Num país em que 'custa alto' ser índio ou negro (...) a autoatribuição de identidade vem acompanhada de demandas pela manutenção ou recuperação de direitos, sobretudo do acesso à terra" (RATTS, 2004, p.79), como na reflexão proposta no texto em questão.

Certa vez um jovem quilombola e pescador do Guaí, no município de Maragogipe (BA), afirmou que a defesa dos territórios é, na verdade, a luta pela defesa da sua vida, bem como das suas e dos seus. Essa narrativa é constante nas bocas e nas expressões do cotidiano de diversas pessoas nos territórios quilombolas e pesqueiros, isso se dá pela também constante violência experimentada nesses territórios. Os projetos de desenvolvimento, legitimados pela falsa indiscutibilidade da ideia de progresso, são os principais antagonistas do modo de vida quilombola e pesqueiro na Bahia. Esses projetos atuam em diversos segmentos, indo desde a implantação de estaleiros, de carciniculturas, da extração de produtos oriundos do petróleo, da mineração até os megaprojetos do turismo.

Por sua vez, os projetos atuam no sentido de expulsar as comunidades ou de afetar significativamente o modo de vidas dessas para substituí-las por um modelo que se arvora garantir o desenvolvimento e o progresso. Para que o desenvolvimento seja alcançado lança-se mão do projeto colonial que tenta hierarquizar e subjugar os povos, cujos territórios devem ser redirecionados aos interesses dos colonizadores, nas palavras de Vandana Shiva: "o desaparecimento do saber local por meio de sua interação com o saber ocidental dominante acontece em muitos planos, por meio de muitos processos. Primeiro fazem o saber local desaparecer simplesmente não o vendo, negando sua existência." (SHIVA, 2003, p.23).

Boa parte das (os) quilombolas possuem o modo de vida integrado a natureza, ou como afirma Antônio Bispo dos Santos, o nego Bispo, possuem uma "relação comunitária e biointerativa (...) com os seus territórios" (SANTOS, 2019, p.70) no sentido de garantir a circularidade de suas vidas nos aspectos sociais, culturais e de subsistência, com atividades de baixo impacto a natureza, resultantes dessa biointeratividade (SANTOS, 2019). Possui baixa inserção no mercado formal ou no circuito superior da economia abril de 2020, p. 32-53 
(SANTOS, 2004), vendo o mercado como não-determinante para o seu modo de vida. Boa parte dos povos e comunidades tradicionais não possuem documentos de propriedade para fortalecer a posse do território (CAÑETE; CAÑETE, 2011). Porém, o principal critério para a identificação destas é a autoatribuição (ou autodefiniç̧ão).

É nesse cenário no qual estão inseridos os quilombos que com a sua organização são importantes protagonistas do mundo agrário. Entende-se que com o acionamento da identidade quilombola, o território quilombola deve passar a ser preservado, pois segundo a Constituição Federal de 1988 é garantida através do Art. 68 do Ato das Disposições Constitucionais Transitórias (ADCT) a dominialidade das terras tradicionalmente ocupadas: “Aos remanescentes das comunidades dos quilombos que estejam ocupando suas terras é reconhecida a propriedade definitiva, devendo o Estado emitir-lhes os títulos respectivos". O ADCT passa a ser regulamentado pelo Decreto $n^{\circ} 4.887 / 2003$, o qual define "Os procedimentos administrativos para a identificação, o reconhecimento, a delimitação, a demarcação e a titulação da propriedade definitiva das terras ocupadas por remanescentes das comunidades dos quilombos (...)” (BRASIL, 2003).

Duas contribuições da legislação quilombola são destacadas aqui. A primeira faz referência a prioridade dada ao critério de autoatribuição. Na prática, a autoatribuição se dá a partir do reconhecimento coletivo e individual: individual porque o/a sujeito se reconhece enquanto quilombola; coletivo porque a comunidade o/a reconhece enquanto pertencente ao grupo. Outra questão importante é que com o Decreto 4.887/2003 há uma alteração no significado do termo quilombo, pois se outrora quilombo era considerado como uma organização criminosa, sendo perseguida legislativamente, com o Decreto esse termo ganha um sentido capaz de conferir legislativamente direitos e garantias sociais as e aos sujeitos que assim se autodenominam.

Vive-se um momento no qual cada vez mais comunidades reivindicam a identidade quilombola. Segundo os dados da Fundação Cultural Palmares (2017), existem 2.997 comunidades remanescentes de quilombos no Brasil. Destas, 2.523 possuem a certidão de autodefinição quilombola emitida pela Fundação Cultural Palmares (Mapa 1). No Estado da Bahia existem 763 comunidades remanescentes de quilombos; destas, 613 possuem a certidão quilombola. 
Mapa 1: Comunidades quilombolas no Brasil até o ano de 2017

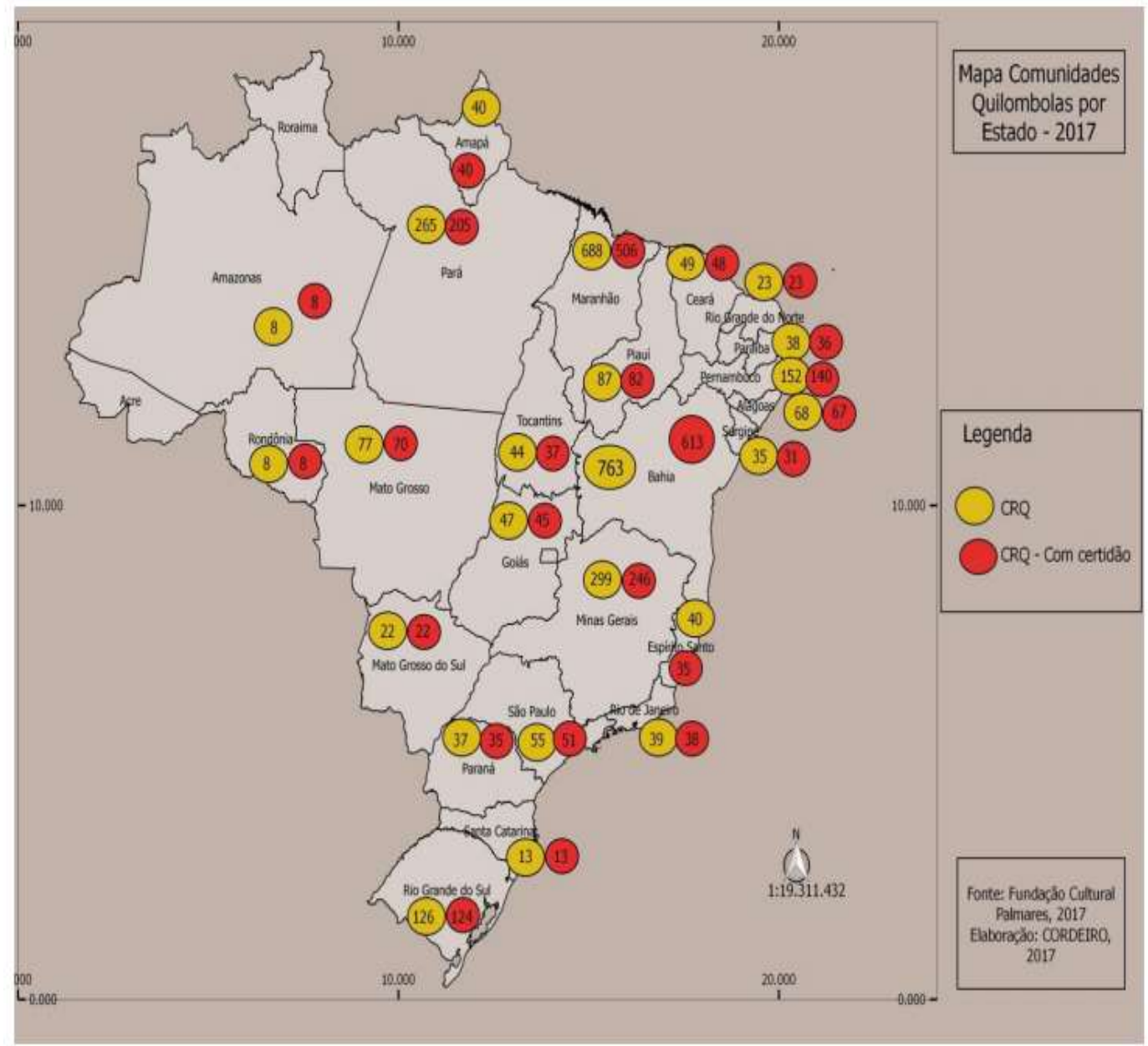

Fonte: CORDEIRO, 2019, p.64.

Os fatores para esse crescimento são diversos, mas, sem dúvida, boa parte dos quilombos aciona a identidade em contextos de conflitos territoriais, nos quais a identidade se revela como garantidora de direitos. É, portanto a partir do choque com a

Revista da ABPN • v. 12, n. Ed. Especial - Caderno Temático: "Geografias Negras"• abril de 2020, p. 32-53 
tentativa de apropriação privada de seus territórios que boa parte das comunidades (re)constrói sua identidade. Ou como nos diz Frantz Fanon: "Enquanto o negro estiver em casa não precisará, salvo por ocasião de pequenas lutas intestinas, confirmar seu ser diante de um outro." (FANON, 2008, p.103).

Segundo a legislação vigente, essa (re)construção identitária deveria levar às políticas sociais, culturais e territoriais. Porém, durante a análise da situação fundiária das comunidades quilombolas da Bahia percebe-se que o Estado não tem atuado no sentido de garantir os direitos territoriais. Nesse sentido, esse artigo pretende investigar se a nãoregularização dos territórios tradicionais quilombolas ${ }^{2}$, ou melhor, se a não-proteção ${ }^{3}$ possui relação com o racismo, mais precisamente com o racismo estrutural.

\section{TERRITÓRIOS QUILOMBOLAS}

O território quilombola é compreendido pelos sujeitos sociais quilombolas como o espaço necessário à reprodução cultural, religiosa, social, ancestral e econômica, sendo a base da organização social e da identidade cultural de grupos negros. Alex Ratts (2004) alerta que onde há identidade, o confronto está presente:

o "jogo de espelhos" da identidade nos remete igualmente a um quadro complexo que se desdobra em situações e escalas variadas. Os encontros ou reencontros entre índios, negros e os outros quase sempre tornam-se confrontos perceptíveis nos planos da linguagem, dos códigos simbólicos e da dimensão espacial. Não raramente emergem como conflitos territoriais e étnicos. Os outros aqui referidos o são sempre dentro de um quadro situacional, relacional ou contextual. (RATTS, 2004, p. 80).

Ao pensar com Alex Ratts, pode-se concluir que o território quilombola é também um espaço de disputas e conflitos. Portanto o território quilombola está localizado no confronto entre modos de vida, entre disputas pela produção e reprodução de determinada

2 As comunidades estudadas aqui são também pesqueiras, no entanto, por não haver procedimento legal constituído para a regularização dos territórios pesqueiros destas, darei ênfase para o processo de regularização fundiária quilombola.

3 Os territórios das comunidades de quilombos devem ser protegidas e receber políticas públicas sendo regularizadas ou não.

Revista da ABPN • v. 12, n. Ed. Especial - Caderno Temático: "Geografias Negras"• abril de 2020, p. 32-53 
porção do espaço. É na disputa, no confronto entre os poderes que o território quilombola ganha contornos e novos relevos.

Fato comprobatório é que conjuntamente com a crescente autoatribuição dos povos vivencia-se um quadro da não-titulação dos territórios quilombolas. Segundo o decreto 4.887/2003, há procedimentos para a identificação, o reconhecimento, a delimitação, a demarcação e a titulação da propriedade definitiva das terras ocupadas por remanescentes das comunidades dos quilombos.

O processo de organização das comunidades quilombolas em torno da identidade quilombola é, sem dúvida, o primeiro momento da regularização fundiária dos territórios quilombolas e representa, muitas vezes, o momento de intensificação dos conflitos. Posteriormente a associação comunitária solicita a certidão de autodefiniç̧ão quilombola a Fundação Cultural Palmares. A comunidade apresenta a certidão ao Instituto de Colonização e Reforma Agrária (Incra). Após dar entrada no Incra a primeira etapa para a regularização do território é a elaboração do Relatório Técnico de Identificação de Delimitação (RTID), que consiste em levantamentos e estudos fundiários, cartográficos, antropológicos, ecológicos, geográficos, socioeconômicos, históricos obtidos em campo e junto a instituições de caráter público ou privado. O objetivo principal do RTID é identificar os limites dos territórios das comunidades quilombolas.

A fase seguinte é a publicação do RTID, no qual os interessados terão 90 dias para contestarem o Relatório junto à Superintendência Regional do Incra. Do julgamento das contestações caberá recurso único ao Conselho Diretor do Incra, no prazo de 30 dias. A próxima fase é a portaria de reconhecimento, no qual há a publicação de portaria do Presidente do Incra no Diário Oficial da União (DOU) e dos estados. Na publicação estará descrita os limites do território quilombola. Após a publicação, caso existam imóveis privados (títulos ou posses) no território tradicional, é necessária a publicação de Decreto Presidencial de Desapropriação por Interesse Social. Esses imóveis serão vistoriados e avaliados conforme o preço de mercado e receberão indenização em dinheiro.

A titulação do território é o coroamento desse processo. Aqui o presidente do Incra realizará a titulação mediante a outorga de título coletivo, imprescritível e pró-indiviso à comunidade, em nome da associação comunitária. Apesar de poder ser sintetizado em 
poucas linhas, o caminho pela titulação percorrido pelas comunidades quilombolas pode se arrastar no tempo. Os dados mostram o número reduzido de comunidades quilombolas que conseguem chegar a fase final, ou seja, que conquistam a titulação quilombola.

Se de 2005 até 2017 foram emitidas 2.455 certidões quilombolas, segundo os dados do Incra, no mesmo período, foram elaborados 259 RTIDs, com a publicação de 82 decretos, 141 portarias e emissão de 116 títulos, destes 99 são títulos parciais e apenas 17 quilombos tiveram a titulação completa de seus territórios (Quadro 1).

Quadro 1: Dados da Regularização Fundiária no Brasil 2005-2017

\begin{tabular}{|r|r|r|r|r|r|}
\hline \multirow{2}{*}{ Certidões Quilombolas } & \multirow{2}{*}{ RTID Elaborados } & \multirow{2}{*}{ Decretos } & Portarias & \multicolumn{2}{|c|}{ Títulos } \\
\cline { 4 - 6 } & & & & Parciais & Integral \\
\hline $2.455(100 \%)$ & $259(10 \%)$ & $82(3 \%)$ & $141(6 \%)$ & $99(4 \%)$ & $17(0,7 \%)$ \\
\hline
\end{tabular}

Na Bahia, no mesmo período foram certificadas 596 comunidades quilombolas, destas, no período entre 2004 e 2018, 319 comunidades abriram processos no Incra para a regularização fundiária, segundo dados do Incra entre 2005 e 2018, 37 comunidades possuem processos em andamento, destas 16 possuem RTIDs elaborados ou em fase de elaboração, 7 possuem a portaria publicada, 8 possuem decretos publicados, 3 possuem a Concessão do Direito Real de Uso (CDRU), apenas 3 possuem a titulação parcial dos seus territórios e nenhum quilombo possui a titulação integral de seu território, o que significa que na Bahia existem 245 processos paralisados no Incra, ou melhor existem 245 territórios (76,80\%) esperando por regularização fundiária (Quadro 2).

Quadro 2: Dados da Regularização Fundiária na Bahia 2005 - 2018

\begin{tabular}{|c|c|c|c|c|c|c|c|c|c|}
\hline \multirow{2}{*}{ Certidöes Quilounbolas } & \multirow{2}{*}{ Entrada no Inera } & \multirow{2}{*}{ Processo em andamento } & \multirow{2}{*}{ RTID Elaborado } & \multirow{2}{*}{ Portaria (DOU) } & \multirow{2}{*}{ Decreto (DOU) } & \multirow{2}{*}{ CDRU } & \multicolumn{2}{|c|}{ Titulo } & \multirow{2}{*}{ Processo paralisado } \\
\hline & & & & & & & Parcial & Integral & \\
\hline 596 & $319(100 \%)$ & $37(11,6 \%)$ & $16(5,01 \%)$ & $72.19)$ & $8(2.5(\%)$ & $3(0,94 \%)$ & $3(0,948)$ & 0 & $245(76,80 \times)$ \\
\hline
\end{tabular}

Obs: Os dados referentes as certidões quilombolas são do período de 2004 a 2017.Fonte: Incra, 2019 Elaboração: CORDEIRO, 2019

Fonte: INCRA, 2018

Revista da ABPN • v. 12, n. Ed. Especial - Caderno Temático: "Geografias Negras"• abril de 2020, p. 32-53 
É perceptível a disparidade entre o reconhecimento da identidade quilombola e a garantia de seus direitos territoriais. Os dados apresentados acima são alarmantes, pois mostram a negligência com que estão sendo tratados os territórios quilombolas no Brasil. Se no Brasil, até 2017 existiam apenas 116 titulações territoriais esse número piora quando se percebe que destes apenas 17 possuíam a titulação integral de seus territórios. $\mathrm{Na}$ Bahia, território com expressiva concentração quilombola, nenhum quilombo teve seus direitos territoriais respeitados. A não titulação ou a titulação parcial dos territórios quilombolas se tornou norma nos processos de regularização fundiária, contrariando o decreto 4.887/2003, deixando esses territórios vulneráveis e atuando no sentido de conferir legalidade às invasões externas aos territórios quilombolas.

Em pesquisa pode-se perceber que todos os 37 quilombos que estão com processos em andamento no Incra, na Bahia, possuem conflitos territoriais, incluindo aqueles com titulação parcial do território. As situações de conflito variam desde a tentativa de expulsão e violência por fazendeiros, quanto por implantações de megaempreendimentos como a Ferrovia de Integração Oeste-Leste (FIOL), o Porto de Aratu, áreas de extração de gás natural, petróleo e minérios, por conflitos com as forças $\operatorname{armadas}^{4}$, além de conflitos causados pela expansão do turismo nos territórios tradicionais.

A não-regularização fundiária destes territórios na Bahia é fruto do entendimento de que esses devem estar disponíveis para o mercado. Essa visão da propriedade privada da terra é fruto da organização do sistema-mundo moderno-colonial (QUIJANO, 2005). Para a constituição do mundo moderno-colonial vivenciado atualmente, foi necessário o estabelecimento de normatizações que visavam assegurar o poder político, econômico, social e cultural do europeu e posteriormente norte-americano sobre o restante do globo.

Para isso, como já demonstrou Yves Lacoste (1988), o controle territorial é

4 Como no caso do Quilombo Rio dos Macacos, em conflito desde pelo menos a década de 1970 com a Marinha do Brasil. O território tradicional de Rio dos Macacos foi reduzido de 301 hectares para 104 hectares e teve a portaria publicada no Diário Oficial da União (DOU). Um estudo fora realizado em Dissertação de mestrado em 2018, com o título: "Essa terra é para fill@@s e net@s, não vende e não pode trocar: A disputa entre o território tradicional quilombola-pesqueiro de Rio dos Macacos e o território militarizado da Marinha do Brasil”. 
indispensável. Assim, lançou-se mão da hierarquização e subjugação dos povos cujos territórios deveriam ser redirecionados aos interesses dos colonizadores. A medida que o saber local consegue se restabelecer e re-existir ocorre a tentativa de descaracterizá-lo, subjugando-o novamente:

Quando o saber local aparece de fato no campo da visão globalizadora, fazem com que desapareça negando-lhe o status de um saber sistemático e atribuindolhe os adjetivos de "primitivo" e anticientífico. Analogamente o sistema ocidental é considerado o único "científico e universal". Entretanto, os prefixos "científico" para os sistemas modernos e "anticientífico" para os sistemas tradicionais de saber tem pouca relação com saber e muita com poder (SHIVA, 2003, p. 23).

Com a pretensão de tornar-se universal, o atual sistema criou um imaginário de neutro, científico e moderno, segundo Shiva (2003):

(...) o sistema dominante também é um sistema local, com sua base social em determinada cultura, classe e gênero. Não é universal em sentido epistemológico. É apenas a versão globalizada de uma tradição local extremamente provinciana. Nascidos de uma cultura dominadora e colonizadora, os sistemas modernos de saber são, eles próprios, colonizadores. (SHIVA, 2003, p. 22).

A ideia de moderno e de progresso afirma que todas as sociedades têm um destino em comum: o desenvolvimento. E, para que o desenvolvimento seja alcançado é necessário que os territórios estejam disponíveis para o seu principal agente: o mercado. A não-regularização, ou melhor, a não proteção dos territórios quilombolas torna-se norma.

\section{TERRITÓRIOS QUILOMBOLAS E RACISMO}

O conflito em torno dos territórios quilombolas é parte do processo de expansão das fronteiras do capital. Essas fronteiras do capital necessitam romper, fragmentar, avançar sobre as fronteiras étnicas, sejam elas dos povos indígenas, quilombolas, pescadores, fundos e fechos de pasto ou de outras comunidades tradicionais. 


\section{Oensinomern}

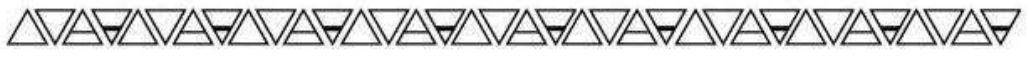

No caso estudado, trata-se de que a população negra é aquela a habitar os territórios quilombolas. A raça não é apenas um dado, mas um fator importante para a compreensão do processo em curso. Renato Emerson dos Santos afirma que:

A raça é um critério básico de classificação da população mundial, fundamental para afirmação do sistema capitalista (QUIJANO, 2007). Sustentada (durante um tempo) ou superada (mais recentemente) pelo saber do campo da Biologia, é sua pertinência social em projetos de poder que sustenta sua permanência, a despeito de ter ou não ter lastro em saberes científicos. É neste sentido que mesmo com a negação da pertinência de diferenças biológicas entre seres humanos que permitam sua classificação em grupos raciais, no cotidiano das relações sociais a raça continua a ser um princípio regulador de comportamentos e relações: reconhecer a igualdade biológica não necessariamente impulsiona reconhecimento de igualdade social (SANTOS, 2017, p. 59).

A expulsão, a apropriação privada e a negação de direitos aos povos negros e indígenas estão na gênese da formação socioespacial brasileira e apesar das conquistas inscritas na Constituição Federal de 1988, a hierarquização das populações através da raça e etnia continua a transformar os territórios dessas populações em algo que merece ser conquistado, quando não colonizado. Carlos Moore, afirma que “(...) o fenótipo, desde os mais longínquos períodos, determina um papel orientador das ações de violência iniciadas por disputas de recursos e território entre populações visivelmente diferentes" (MOORE, 2012, p.130).

A operacionalização do racismo serve, portanto, para assegurar a propriedade e preservação monopolista das riquezas vitais da sociedade (MOORE, 2012). No caso do Brasil, o qual está inserido na divisão internacional do trabalho como um país exportador de commodities, os territórios com maiores riquezas naturais, possuem então as riquezas vitais da nossa sociedade. Em texto recente, Paulo Alentejano afirma que:

A tropicalidade (abundância de sol e água) dominante em nosso território garante a intensidade dos processos de fotossíntese, acelerando o metabolismo das plantas e seu processo de crescimento, o que favorece ainda mais à acumulação de capital na agricultura, por contribuir para reduzir a diferença entre tempo de trabalho e tempo de produção (ALENTEJANO, 2015, p. 06).

Revista da ABPN • v. 12, n. Ed. Especial - Caderno Temático: "Geografias Negras"• abril de 2020, p. 32-53 
As palavras de Alentejano reafirmam a compreensão de que os conflitos fundiários, com destaque para os conflitos nos territórios quilombolas são uma necessidade de expansão do capital. O racismo, assim como o capital evolui constantemente (CÉSAIRE, 1971), se outrora fora a escravização, ou a Lei de Terras de $1850^{5}$, a atual necessidade da exploração intensa e mecanizada da natureza coloca mais uma vez a necessidade dos sujeitos hegemônicos em negar e exterminar o diferente.

Dessa forma, ora afirmam as comunidades quilombolas como atrasadas, como impedimento ao desenvolvimento, necessitando serem estas superadas, ora tentam descaracterizá-las. Isso é percebido nas palavras de Jair Bolsonaro, atual presidente da República que em 2017 demonstra suas impressões sobre uma comunidade quilombola em Eldorado (São Paulo): “O afrodescendente mais leve lá pesava sete arrobas. Não fazem nada. Eu acho que nem para procriar eles servem mais" (BRASIL DE FATO, $2019)^{6}$.

Da mesma forma que as instituições nacionais da então recém República brasileira “(...) defendiam que o desenvolvimento e o crescimento da República - fundada em 1889 - estariam vinculados ao branqueamento da sua população" (CORRÊA, 2017, p.117). Os capitalistas brasileiros e estrangeiros defendem que o desenvolvimento e o progresso da atual república só existirão quando a propriedade da terra seja assegurada a quem der lucro. Novamente reproduz-se as palavras de Jair Bolsonaro:

Seu povo, seus irmãos, têm problemas. E o grande problema chama-se governo federal. Eles querem ser libertos, para ter liberdade para poder trabalhar dentro da sua comunidade, acho até que se quiser vender aquela área quilombola, que venda, opinião minha. Se quiser explorar, tirar por exemplo minério, ter maquinário, a exemplo do seu irmão fazendeiro do lado, se quiser, poder explorar de forma racional seus recursos naturais igual ao fazendeiro do lado. (OGLOBO, 2018)7.

\footnotetext{
$5 \quad$ A Lei de Terras de 1850 é conhecida por ter antecedido e preparado a propriedade privada para não absorver os africanos escravizados que seriam libertos em 1888, com a abolição formal da escravatura. ${ }^{6}$ Ver matéria completa em: https:/www.brasildefato.com.br/2019/06/07/quilombolas-que-foram-alvo-debolsonaro-criticam-arquivamento-de-processo-de-racismo/.

7 Ver matéria completa em: https://oglobo.globo.com/brasil/bolsonaro-defende-que-areas-quilombolaspossam-ser-vendidas-22859321.
} abril de 2020, p. 32-53 
Não é de se espantar que um país que até a Constituição de 1945 possuía decretos e artigos que afirmavam a importância da imigração para o branqueamento da nação ${ }^{8}$ produza argumentos para a Ação Direta de Inconstitucionalidade (ADI) 3239 - a ADI quilombola - e para a não-regularização (e não-proteção) dos territórios quilombolas.

A ADI 3239 discute a constitucionalidade do já citado Decreto Federal $n^{\mathbf{o}}$ 4887/03 ${ }^{9}$, ajuizada em 2004 pelo Partido da Frente Liberal (PFL), atual Democratas, contém 11 volumes e 1600 páginas. A ADI quilombola questiona dois princípios fundamentais do Decreto, o primeiro é o critério de autoatribuição para a identificação de quilombos e o segundo é a existência de "critérios de territorialidade indicados pelos remanescentes das comunidades de quilombos" para medição e demarcação destas terras $\left(\right.$ art. $2^{\circ}, \S 3^{\circ}$ ). Após 14 anos, o Supremo Tribunal Federal (STF) declarou a validade do Decreto 4.887/2003, a Ação Direta de Inconstitucionalidade 3239 foi julgada improcedente por oito ministros. O ministro e relator do caso Cezar Peluso (aposentado), foi o único voto pela total procedência da ação. Cezar Peluso afirma que não se poderia ignorar o crescimento de conflitos agrários e que o Decreto 4.887/2003, por representar a usurpação de direitos de propriedade privada, pode levar o incitamento à revolta.

A decisão do relator demonstra que não há compreensão dos quilombolas enquanto sujeitos de direitos, mas sim como usurpadores de direitos de propriedade privada. A questão que se coloca é entender que a propriedade da terra no Brasil sempre foi reconhecida para aqueles que detinham o poder político e econômico ao longo do tempo. Sem dúvida, essas pessoas não são negras, nem indígenas. O racismo opera aqui com seu caráter institucional. Nesse sentido, segundo Sílvio Almeida: "o poder é elemento constitutivo das relações raciais, mas não somente o poder de um indivíduo de uma raça sobre outro, mas de um grupo sobre outro, algo possível quando há o controle direto ou indireto de determinados grupos sobre o aparato institucional" (ALMEIDA, 2018, p. 36).

\footnotetext{
8 “Atender-se-á, na admissão dos imigrantes, à necessidade de preservar e desenvolver, na composição étnica da população, as características mais convenientes da sua ascendência europeia, assim como a defesa do trabalhador nacional." (DECRETO N.7.967, 1945)

${ }^{9}$ Decreto que regulamenta o procedimento de titulação dos territórios quilombolas no Brasil.
} abril de 2020, p. 32-53 
Ao tentar romper essa ordem da organização da propriedade privada, os quilombos no Brasil ameaçam romper também a ordem racial do poder. É necessário remeter as palavras de Vandana Shiva, algumas linhas acima, contextualizando com a situação vivenciada pelos quilombos na contemporaneidade. A história dos quilombos no Brasil podem ser divididas em três momentos: (I) perseguição, punição e criminalização até 1888, com a abolição da escravatura (MOURA, 1981); (2) apagamento no pósabolição até aproximadamente a década de 1970 (ANJOS, 2004); (3) emergência e consolidação de direitos com a Constituição Federal de 1988. Se desde a introdução dos primeiros africanos escravizados no Brasil reinou a tentativa de apagamento cultural, através da aculturação ou do genocídio, a partir da abolição da escravatura a tentativa foi de apagar os sujeitos que foram subalternizados "simplesmente não o[s] vendo, negando sua[s] existência[s]" (SHIVA, 2003, p.23) e quando essas existências "aparece[m] de fato no campo da visão globalizadora, fazem com que desapareça[m]” (SHIVA, 2003, p.23).

O questionamento em relação a autoatribuição na ADI 3239 é uma manifestação à nível nacional do que acontece nos territórios. O questionamento da identidade quilombola é constante nos processos de regularização fundiária, principalmente quando esses territórios estão em conflitos. Se a ADI 3239 foi derrubada, o questionamento ocorre nos territórios mesmo quando os quilombos apresentam a certidão emitida pela Fundação Cultural Palmares.

$\mathrm{Na}$ Bahia, por exemplo, inúmeros quilombos se deparam com esse questionamento. O Quilombo Rio dos Macacos, localizado no município de Simões Filho, em conflito com a Marinha do Brasil teve sua identidade questionada pelo juiz Evandro Reimão que ao julgar uma ação da Marinha afirma serem os quilombolas ocupantes ilegais que se escondem por trás da identidade quilombola. Além do juiz, a Revista Veja em maio de 2014 publicou a notícia com o título "O falso quilombo do ministro", reafirmando a tese de que a identidade quilombola na comunidade de Rio dos Macacos seria falsa (Figura 1).

Figura 1: Reportagem da Revista Veja em 2014 


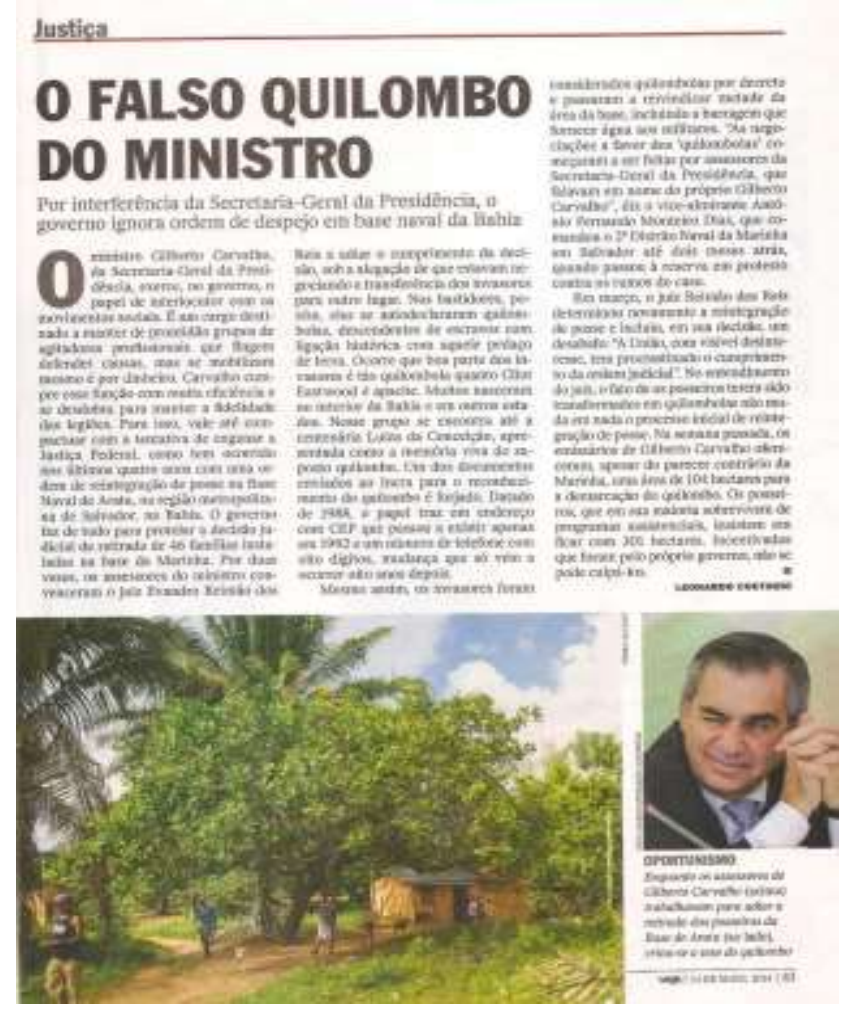

Fonte: Veja, 2014, p.83

O território quilombola de São Francisco do Paraguaçu, situado no município de Cachoeira, em conflito com fazendeiros oriundos das oligarquias nacionais também teve sua identidade questionada. Foram diversas tentativas de ações de reintegração de posse ordenadas pelas justiças estadual e federal e ações violentas levadas a cabo por jagunços e policiais da Polícia Militar (PM) do Estado da Bahia. Todas as ações tinham como princípio o questionamento seguido de negação da identidade quilombola. Além dos impedimentos ocasionados pela articulação dos fazendeiros com a justiça, entrou em cena a TV Globo, que em reportagem veiculada em $2007^{10}$ afirmou que houve fraude na emissão da certidão da Fundação Cultural Palmares, pois segundo a emissora, a identidade quilombola em questão é falsa.

10 Link para reportagem: https:/www.youtube.com/watch?v=Y6C1YtZQBq0

Revista da ABPN • v. 12, n. Ed. Especial - Caderno Temático: "Geografias Negras"• abril de 2020, p. 32-53 


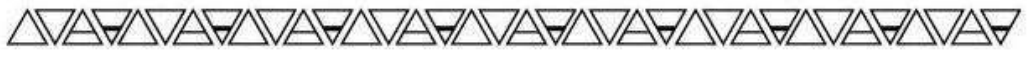

Figura 2: Reportagem da TV Globo em 2007

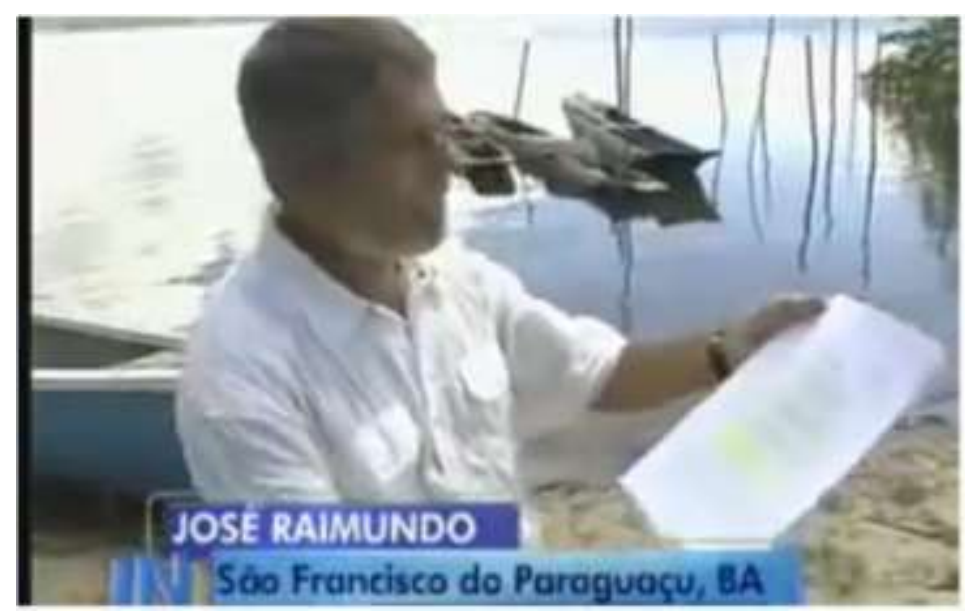

Fonte: Globo, 2007.

No Baixo Sul da Bahia, no município de Taperoá, o quilombo de Graciosa em conflito com a expansão do turismo e da privatização das áreas de pesca e de agricultura também teve o processo de regularização fundiária interrompido pela decisão judicial do juiz Evandro Reimão questionando e negando também a condição desses enquanto quilombolas. Esse mesmo juiz também afirmou a condição de falsa a identidade quilombola da comunidade de Dom João, no município de São Francisco do Conde. Nessa comunidade, o conflito se instaura tanto pela presença de fazendeiros, pelos derramamentos de resíduos da Petrobras, quanto pela construção de autódromo pelo Governo do Estado da Bahia.

Poder-se-ia passar muitas linhas pelo tortuoso caminho percorrido pelos quilombos na Bahia, mas se da emissão da certidão da Fundação Cultural Palmares até a elaboração do RTID o rio corre e muitas vezes não chega a foz, o mesmo acontece quando há a publicação dos Relatórios dessas comunidades.

Por exemplo, em 2012, o Incra apresentou o RTID do quilombo Rio dos Macacos e identificou 301 hectares como território quilombola. No entanto, segundo os quilombolas sua territorialidade chega até a 900 hectares. Sendo publicado em 2014, após abril de 2020, p. 32-53 
exigência do Ministério Público Federal, o território a ser destinado para a titulação abarca 104 hectares desfragmentados ${ }^{11}$.

O mapa abaixo (Mapa 3), apresenta a desfragmentação do território. A linha preta representa os 301 hectares inicialmente reconhecidos pelo Incra já as poligonais brancas representam os 104 hectares. O território será dividido em duas glebas sem continuidade e articulação territorial: a primeira, localizada na área norte-noroeste do território, possui 98,2755 ha; a segunda possui 5,8057 ha e está localizada a sudoeste. A princípio essa proposta ignora e desrespeita a decisão quilombola contrária à fragmentação territorial. Não se trata apenas da questão quantitativa do território, mas também das questões culturais e identitárias: a existência de um território contínuo no Quilombo - "Um Quilombo só", é condição necessária para a sua reprodução. A fragmentação desencadeará um processo de fratura ou quebra, o território que era um se transformará em dois fragmentos, são duas partes quebradas, isoladas, desunidas, desconectadas. Atualmente a comunidade possui portaria publicada no Diário Oficial da União (DOU).

Mapa 2: Fragmentação do território quilombola de Rio dos Macacos

\footnotetext{
11 Um estudo fora realizado em Dissertação de mestrado em 2018, com o título: "Essa terra é para filh@s e net@s, não vende e não pode trocar: A disputa entre o território tradicional quilombola-pesqueiro de Rio dos Macacos e o território militarizado da Marinha do Brasil".
}

Revista da ABPN • v. 12, n. Ed. Especial - Caderno Temático: “Geografias Negras” • abril de 2020, p. 32-53 


\section{Quilombo Rio dos Macacos - Bahia}
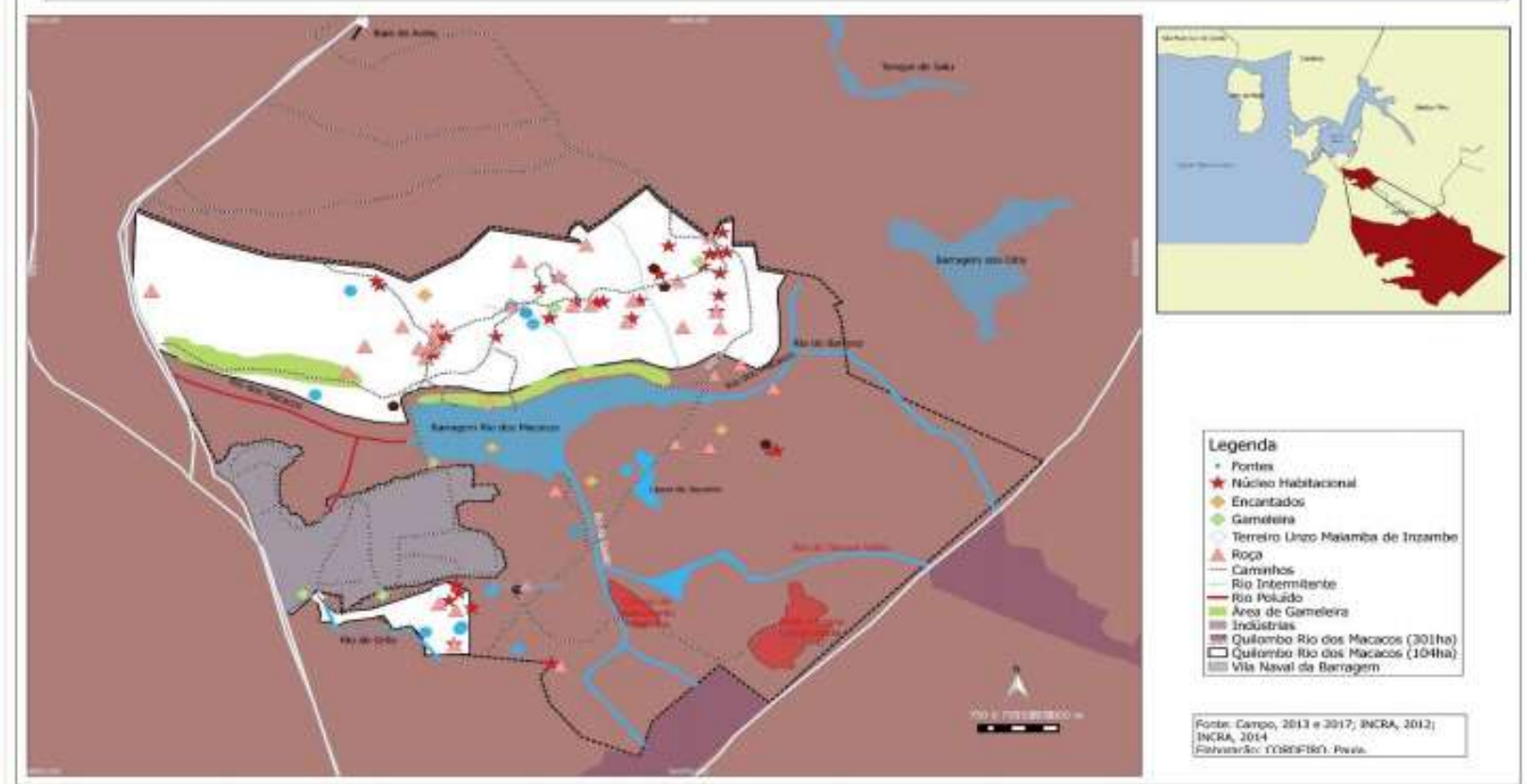

Fonte: Cordeiro, 2019, p.151.

Existem também na Bahia três quilombos que possuem a titulação parcial dos seus territórios, como fora visto anteriormente, nenhum quilombo apresenta a titulação territorial integral. Essa situação revela não apenas o não cumprimento da Constituição Federal de 1988, mas de que há algo mais poderoso que a carta magna, aqui esse "algo" é o racismo. Este entendido não apenas como institucional, mas como racismo estrutural.

Segundo Silvio Almeida:

(...) se é possível falar de um racismo institucional, significa que, de algum modo, a imposição de regras e padrões racistas por parte da instituição é de alguma maneira vinculada à ordem social que ela visa resguardar. Assim como a instituição tem sua atuação condicionada a uma estrutura social previamente existente - com todos os conflitos que lhe são próprios -, o racismo que esta instituição venha a expressar é também parte desta mesma estrutura. As instituições são apenas a materialização de uma estrutura social ou de um modo de socialização que tem o racismo como um de seus componentes orgânicos. Dito de modo mais direto: as instituições são racistas porque a sociedade é racista (ALMEIDA, 2018, p. 36).

Revista da ABPN • v. 12, n. Ed. Especial - Caderno Temático: "Geografias Negras" • abril de 2020, p. 32-53 

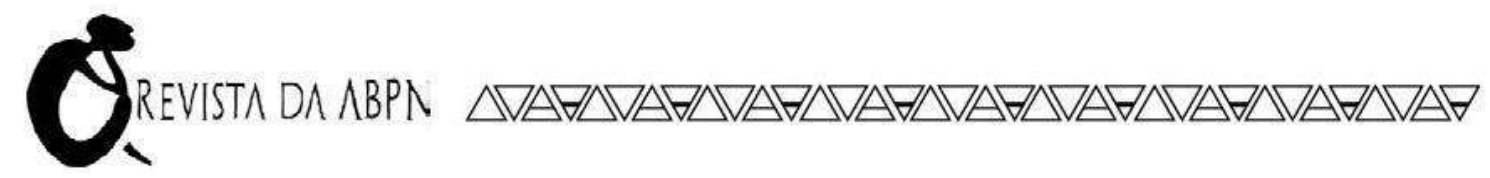

Falar de racismo estrutural não é afirmar que o racismo é intocável ou inquestionável. Ao contrário, a sociedade é formada por relações de poder envolvendo não apenas raças e etnias, mas colocando em intersecção a classe, o gênero, a sexualidade, a geração, etc. Todos vão gerar inúmeros conflitos e tensões. Essa tensão é também capaz de incidir sobre o padrão de funcionamento de determinadas instituições que privilegiam determinados grupos sociais. Significando "que as instituições também podem atuar de maneira conflituosa, posicionando-se dentro do conflito" (ALMEIDA, 2018, p, 37), ou também que há tensão dentro das instituições.

No caso dos quilombos essa tensão é notada constantemente. Ao considerar o recorte temporal entre os anos de 1970 até os dias atuais, em 2019, percebe-se que a potência dos movimentos quilombolas, articulados a outros movimentos de re-existências do campo e da cidade, aos parlamentares, universidades, artistas e outros setores da sociedade, conseguiram afirmar a importância constitucional do Art. 68 da Constituição Federal de 1988 e do Decreto 4.887/2003. Ao mesmo tempo, pela força da presença daqueles setores que também se articulam para manterem os privilégios existem os ataques e a obstrução de políticas que ao combaterem o racismo, combatem também a sociedade que o produz.

\section{CONSIDERAÇÕES FINAIS}

A não-proteção dos territórios quilombolas e, mais do que isso, a própria compreensão de que os e as quilombolas não são importantes para a constituição da nação, se apresenta quando são desvelados os dados sobre a regularização fundiária no Brasil. A Bahia, território com maior quantitativo de comunidades quilombolas certificados pela Fundação Cultural Palmares apresenta inúmeros casos em que o impedimento do processo de regularização fundiária impacta violentamente não apenas o território ou a natureza, mas também os corpos dos negros e negras aquilombadas.

A obstrução dos procedimentos nas mais diversas etapas da regularização fundiária, quando não questionada não contribui para a constituição de uma nação que respeite os direitos dos povos e das comunidades tradicionais, dentre eles os quilombos,

Revista da ABPN • v. 12, n. Ed. Especial - Caderno Temático: "Geografias Negras"• abril de 2020, p. 32-53 
conforme se compromete o Brasil através de diversos acordos internacionais, como a Convenção 169 da Organização Internacional do Trabalho.

É necessário assumir que o racismo está presente na vida cotidiana na sociedade brasileira, incluindo aqui as instituições. Se a ordem é racista, as instituições são também racistas, como já foi afirmado no tópico anterior. Assim, “em uma sociedade em que o racismo está presente na vida cotidiana, as instituições que não tratarem de maneira ativa e como um problema a desigualdade racial irão facilmente reproduzir as práticas racistas já tidas como 'normais' em toda a sociedade" (ALMEIDA, 2018, p. 37).

A partir da compreensão apresentada nesse texto é possível afirmar que a nãoregularização dos territórios quilombolas na Bahia e no Brasil é responsabilidade da ordem que mantém e garante que a sociedade e suas instituições reproduzam o racismo estrutural. Essa reprodução não é feita sem tensões de grupos que tentam romper esse ciclo que se arrasta no Brasil e mais especificamente na Bahia desde 1501, quando foi iniciada a colonização das águas e terras de Kirimurêe ${ }^{12}$.

\section{REFERENCIAS}

ALENTEJANO, Paulo. A centralidade da questão fundiária no cenário agrário brasileiro no século XXI. Encontro de Geógrafos da América Latina. 2015.

ALMEIDA, Alfredo Wagner B. Terras tradicionalmente ocupadas. Processos de territorialização e movimentos sociais. Revista Brasileira de Estudos Urbanos e Regionais, vol. 6, n.1, p.9-32, 2004.

ALMEIDA, Silvio. O que é racismo estrutural? Belo Horizonte: Letramento, 2018.

ANJOS, Rafael Sanzio dos. Cartografia e Cultura: Territórios dos remanescentes de quilombos no Brasil. VIII Congresso Luso-Afro-Brasileiro de Ciências Sociais. 2004

BRASIL. Decreto $n^{\circ}$ 4.887. 2003.

BRASIL. Artigo 68 do Ato das Disposições Constitucionais Transitórias. 1988

12 Nome dado pelos Tupinambá ao que atualmente conhecemos por Baía de Todos os Santos, nome rebatizado pelos Portugueses em 1501, após a invasão, colonização, resistência, assimilação e extermínio dos povos indígenas, principalmente dos Tupinambás ali existentes.

Revista da ABPN • v. 12, n. Ed. Especial - Caderno Temático: "Geografias Negras"• abril de 2020, p. 32-53 
CAÑETE, Voyner Ravena Cañete; CAÑETE, Thales Maximiliano Ravena. Por uma sociologia do campo jurídico na/da Amazônia: as populações tradicionais amazônicas em foco. Revista Sociologia Jurídica, n. 13, jul/dez. 2011. Disponível em $<$ https://sociologiajuridicadotnet.wordpress.com/por-uma-sociologia-do-campo-juridiconadaamazonia-as-populacoes-tradicionais-amazonicas-em-foco/>. Acesso em: 16. Jun. 2017.

CARRIL, Lourdes. Quilombo, favela e periferia: a longa busca da cidadania. São Paulo: Annablume; FAPESP, 2006.

CASTRO, Edna. Território, biodiversidade e saberes de populações tradicionais. In CASTRO, PITON (Org). Faces do Trópico úmido: Conceitos e questões sobre desenvolvimento e meio ambiente. Belém: Cejup, 1997. P.221-242.

CESAIRE, Aimé. Discurso sobre o colonialismo. Porto: Poveira, 1971.

CORDEIRO, Paula Regina de O. Essa terra épara filh@s e net@s, não vende e não pode trocar: A disputa entre o território tradicional quilombola-pesqueiro de Rio dos Macacos e o território militarizado da Marinha do Brasil. Dissertação (mestrado) em Geografia. Universidade Federal da Bahia. Programa de Pós-Graduação em Geografia. Salvador, 2019. $206 f$.

CORREAA, Gabriel Siqueira. O branqueamento do território como dispositivo colonialidade do poder: notas sobre o contexto brasileiro. In: CRUZ, Valter do Carmo. Geografia e Giro Descolonial: Experiências, ideais e horizontes de renovação do pensamento crítico. Rio de Janeiro: Letra Capital, 2017.

FANON, Frantz. Pele negra, máscaras brancas. Salvador, BA: EDUFBA, 2008.

Fundação Cultural Palmares. Dados Quilombolas. 2017

INCRA. INSTITUTO NACIONAL DE COLONIZAÇÃO E REFORMA AGRÁRIA. Relatório Técnico de Identificação e Delimitação do Território da Comunidade Quilombola de Rio dos Macacos. Salvador, 2012. . Dados de regularização fundiária do Brasil. 2018

LACOSTE, Yves. A geografia - isso serve, em primeiro lugar, para fazer a guerra. Campinas, SP: Papirus, 1988.

MARTINS, José de Sousa. A chegada do estranho. São Paulo: HUCITEC, 1993.

MOORE, Carlos. Racismo \& Sociedade: novas bases epistemológicas para entender o racismo. 2. Ed. Belo Horizonte: Nadyala, 2012.

MOURA, Clóvis. Rebeliões da senzala: quilombos, insurreições, guerrilhas. 3. ed. São Paulo, SP: Ciências Humanas, 1981.

Revista da ABPN • v. 12, n. Ed. Especial - Caderno Temático: “Geografias Negras” • abril de 2020, p. 32-53 
QUIJANO, Aníbal. Colonialidade do poder, eurocentrismo e América Latina. In: LANDER, Edgardo (Org). A colonialidade do saber: eurocentrismo e ciências sociais. Perspectivas latinoamericanas. Ciudad Autónoma de Buenos Aires, Argentina: CLACSO, 2005. Colección Sur Sur. p. 227-278.

RATTS, Alex. As etnias e os outros: as espacialidade dos encontros/confrontos. In: Espaço e cultura. UERJ, Rio de Janeiro, N 17-18, Jan/Dez de 2004. p.77-89.

SANTOS, Antônio Bispo dos. Colonização, quilombos: modos e significações. Brasília: Ayô, 2019.

SANTOS, Renato Emerson. O movimento negro brasileiro e sua luta antirracismo: por uma perspectiva descolonial. In: CRUZ, Valter do Carmo. Geografia e Giro Descolonial: Experiências, ideais e horizontes de renovação do pensamento crítico. Rio de Janeiro: Letra Capital, 2017.

SEPPIR. Plano Nacional de Desenvolvimento Sustentável dos Povos e Comunidades Tradicionais de Matriz Africana 2013-2015. 2013.

SHIVA, Vandana. Monoculturas da Mente. São Paulo: Gaia, 2003.

Recebido 20/02/2020

Aprovado em 30/03/2020

Revista da ABPN • v. 12, n. Ed. Especial - Caderno Temático: "Geografias Negras"• abril de 2020, p. 32-53 